\title{
STAT3 Gain of Function
}

National Cancer Institute

\section{Source}

National Cancer Institute. STAT3 Gain of Function. NCI Thesaurus. Code C126345.

A mutation in the STAT3 gene that results in an increase in cytokine-related function.

STAT 3 mutations of this type are associated with infantile-onset multisystem autoimmune disease. 